\title{
Compatibility Effects in Evaluations of Satisfaction and Loyalty
}

\author{
Seigyoung Auh \\ Department of Management, University of Melbourne, Babel Building Level 5, Parkville, \\ Vic.3010, Australia
}

Michael D. Johnson

University of Michigan Business School, Ann Arbor, MI, USA

\begin{abstract}
The goal of this research is to help understand the difference between satisfaction and loyalty based on the nature of the judgment tasks involved. By drawing on the notion of the prediction- decision inconsistency, we posit satisfaction as a consumption/experience utility and loyalty as a decision utility to explain the missing link between satisfaction and loyalty. An important assumption that may be driving the predictiondecision inconsistency, but has not been addressed, is the different criteria that consumers use in arriving at the two different types of utilities. The authors argue that this difference affects the compatibility, and resulting influence, of quality versus price information on satisfaction and loyalty evaluations. An empirical study of 183firms using data from the American Customer Satisfaction Index is reported which supports the proposed compatibility effects. Implications for marketing theory and practice are discussed.
\end{abstract}




\section{Introduction}

Customer satisfaction is generally seen as having a simple main effect on loyalty

(Fornell, 1992; Fornell, Johnson, Anderson, Cha, \& Bryant, 1996). Products and services vary in the quality and value provided to customers, which creates differences in customer satisfaction, which in turn creates differences in customer loyalty. Yet the relationship between satisfaction and loyalty has been generally modeled without examining potential contingency factors that may alter the relationship between the two constructs (see Jones \& Sasser, 1995, for exception). The primary goal of this research is to help understand the connection between measures of satisfaction, as a type of experience appraisal, and loyalty, as a type of choice or preference evaluation using a contingency framework. We specifically explore under what conditions the satisfaction-loyalty relationship will become stronger.

By drawing on the notion of the prediction-decision inconsistency, we posit satisfaction as a consumption/experience utility and loyalty as a decision utility to explain the missing link between satisfaction and loyalty (Hsee, 1999; Kahneman \& Varey, 1991). Hsee (1999, p. 555) argued that "people do not always use their predictions of consumption utility to guide their decisions."' An important assumption that may be driving the prediction-decision inconsistency, but has not been addressed, is the different criteria that consumers use in arriving at the two different types of utilities. This contention is further supported by the research of transaction utility advanced by Thaler (1985). His argument centered on the fact that consumers, in addition to how much they need the product (i.e., acquisition utility), purchase products based on the degree to which the purchase is a good bargain or fair value. In light of the above discussion, our central thesis is that when the attributes that are compatible with satisfaction and loyalty are similarly weighed in both evaluations, the satisfaction-loyalty relationship is strengthened.

Recent research on customer satisfaction has taken strides to link this strategically important construct to a chain of events including loyalty (i.e., purchase intention), actual retention, and to ultimately financial bottom line performance metrics such as revenue and profit (Anderson, Fornell, \& Lehmann, 1994; Anderson \& Mittal, 2000; Mittal \& Kamakura, 2001; Rust \& Zahorik, 1993). We welcome the direction in which satisfaction research is progressing in that such research will advance our knowledge of customer satisfaction and related constructs in building a cohesive and holistic framework not only from a theoretical vantage point but also from a managerial perspective.

The focus of our paper is on a particular portion of this satisfaction-profit chain. We specifically look into the relationship between satisfaction and loyalty and two key moderating variables that are likely to vary this relationship. Although we believe that the relationship between satisfaction and loyalty has been extensively scrutinized in the literature (Szymanski, 2001), our understanding as to under what conditions this relationship becomes stronger or weaker is very limited (see however Bloemer \& Kasper, 1995; Mittal \& Kamakura, 2001, for exceptions). Our knowledge of moderating variables that may alter this relationship is very much restricted to macro variables such as the type of industry that firms compete in, the monopolistic nature of the environment, and the difficulty of switching to an alternative option (Jones \& Sasser, 1995). Our paper attempts to build and extend on this knowledge base by introducing additional moderating variables that can paint a clearer picture of our understanding of the relationship between satisfaction and loyalty.

One explanation for variation in the satisfaction-loyalty relationship rests on the nature of the judgment tasks involved. Consider an example in which customers are very satisfied with the quality of the service that they receive from their insurance company. When asked to evaluate overall satisfaction, customers are comfortable weighing their service experience quite heavily in their evaluations. However, when asked about their likelihood of choosing the company over others, it may be difficult to give dimensions such as quality the same weight. Rather, more comparable dimensions such as price may receive greater weight (Nowlis \& Simonson, 1997). This prediction is consistent with a growing body of literature on compatibility effects in judgment and choice research (Payne, Bettman, \& Johnson, 1992; Slovic, Griffin, \& Tversky, 1990).

The goal of this study is to extend research on compatibility effects into a satisfaction context. Specifically, we extend the recent work of Nowlis and Simonson (1997) into a customer satisfaction framework and utilize this compatibility argument to bolster the relationship between satisfaction and 
loyalty. A secondary goal is to demonstrate that the types of compatibility effects found by psychologists in the lab are important and occur when customers evaluate their own experience with actual products and services. The significance of our second goal is underscored by a recent article on the importance and necessity of replication in academia (Hunter, 2001). By building on the remarks forwarded by Hunter (2001), this study uses firm-level data from the American Customer Satisfaction Index (ACSI) survey (Fornell et al., 1996), a national survey of American consumers' experience with products and services, to test the compatibility hypothesis in a customer satisfaction and loyalty context thereby cementing the findings for a broader generalization. The results have important implications for modeling customer satisfaction, the strategies used to create satisfaction, and the use of satisfaction data when making quality improvement decisions.

\section{Customer satisfaction, loyalty, and compatibility effects}

We define customer satisfaction as a cumulative evaluation of a customer's purchase and consumption experience to date (Johnson, Anderson, \& Fornell, 1995; Lervik \& Johnson, 2003; Rust, Zahorik, \& Keningham, 1995). This notion of customer captures consumption and experience utility (Hsee, 1999; Kahneman \& Varey, 1991). In contrast, loyalty is a customer's expectation or predisposition to repurchase from a particular product or service provider. Unlike customer satisfaction, loyalty reflects choice or decision utility (Hsee, 1999; Kahneman \& Varey, 1991). Satisfaction models rest heavily on expectancy-value model (Fishbein \& Ajzen, 1975; Johnson, Gustafsson, Andreassen, Lervik, \& Cha, 2001), where beliefs about the consumption experience (quality dimensions and price) affect customer satisfaction as a type of overall evaluation. Satisfaction, in turn, affects customers' repurchase likelihood and actual retention behavior.

Previous research predicts a simple positive effect of this cumulative satisfaction on loyalty that is strongly supported across industries (Fornell, 1992; Fornell et al., 1996). However, we can also envision situations where satisfaction is high but loyalty may be relatively low. As with our previous insurance example, when asked to evaluate the satisfaction of my insurance, service quality maybe weighed heavily in the evaluation. In such a case, the consideration set is just one, namely the insurance company. In contrast, when asked whether to repurchase or not, the consideration set is no longer just the aforementioned insurance company but may include other insurance companies as well. Hence, one may rely on a particular attribute to make across company comparisons before saying whether one will be loyal or not. Our study attempts to shed light on the satisfaction-loyalty relationship by asserting that the link will be strengthened when attributes used to make satisfaction are similarly weighed to make loyalty evaluations.

We acknowledge that our attempt to address the satisfaction-loyalty link by incorporating moderating variables has been explored by previous researchers. A study by Bloemer and Kasper (1995) goes beyond this simple main effect between satisfaction and loyalty. They found that the relationship between customer satisfaction and loyalty was moderated by the amount of elaboration exerted by respondents on the evaluation of the brand choice. They specifically reported that the positive relationship between customer satisfaction and loyalty was stronger when satisfaction was manifest (e.g., well elaborated on that is a result of explicit evaluation) than latent (e.g., not well elaborated on that results from implicit evaluation). The results of this study imply that not all satisfaction is equal and that different types of satisfaction (i.e., manifest and latent), depending on the amount of elaboration used, will have different effects on loyalty.

Mittal and Kamakura (2001) also address the link between satisfaction and repurchase behavior. Their major findings indicate that despite identical ratings on satisfaction, due to respondent characteristics such as age, education, marital status, sex, and area of residence, significant difference was observed in repurchase behavior. This suggests that consumers that have different characteristics possess different threshold levels and thus different repurchase probabilities. The implication from this research points to segmenting consumers' satisfaction-repurchase behavior relationship based on their demographics characteristics. 
Moreover, behavioral decision research provides both theoretical and empirical rationale for positing more than a simple main effect of satisfaction on loyalty. One of the principal ideas that have emerged from research on consumer judgment and choice is that of constructive processing (Bettman, Luce, \& Payne, 1998; Payne et al., 1992). The constructive view holds that individuals use different strategies, or weight information differently, depending on the situation, task, or response scale involved. The weight of a particular information source is enhanced by its basic compatibility with the response mode. Payne et al. (1992) distinguish between two types of compatibility effects, strategy compatibility and scale compatibility. Strategy compatibility occurs when particular sources of information are more compatible with the type of evaluation or decision required of an individual. Scale compatibility exists when the weight of a stimulus attribute or source of information is enhanced by its basic compatibility with the response scale (Tversky, Sattath, \& Slovic, 1988).

On a general level, compatibility effects are consistent with a variety of similar examples where the weight of a stimulus attribute is enhanced by its compatibility with the response mode (see, for example, Billings \& Scherer, 1988; Payne, Bettman, \& Johnson, 1990). Slovic et al. (1990) provide two theoretical rationales for this compatibility hypothesis. Relying on information that is not compatible with the response often requires additional mental operations, which increase effort and error. A particular response mode may also prime or focus attention on the more compatible features of a stimulus.

Nowlis and Simonson (1997) used strategy compatibility to argue and show that "comparable"' attributes (such as price) are systematically more import in comparison- based tasks (such as choice). Conversely, "enriched"' attributes (such as brand name), which are more difficult to compare, receive greater weight when options are evaluated separately. This prediction is consistent with what we propose here. In our study, we used quality and value 1 (as a proxy for price) as the enriched and comparable attributes, respectively. In line with the attribute-task compatibility argument advanced by Nowlis and Simonson (1997), we expect the effect of quality to be greater than the effect of value in determining satisfaction. Conversely, when trying to explain loyalty, we predict the impact of value to be greater than the impact of quality. Yet the generalizability of Nowlis and Simonson's results to a customer satisfaction and loyalty context remains unclear. The reason for this is because unlike their study, which used the same dependent variable (purchase likelihood) only in different modes (e.g., choice versus rating), our study used two different types of dependent variables (i.e., satisfaction and loyalty). In their studies, the choice task presented subjects with information for two hypothetical alternatives and then asked the subjects to select which of the two they would buy. In the likelihood-rating task, subjects were presented with information on each alternative separately and asked to indicate their purchase likelihood.

However, satisfaction and loyalty are concepts used to model customers' ongoing experiences with actual products and services. They represent distinct and discriminant constructs unlike an identical construct with different response modes. Therefore, our study does not test for preference reversal per se although we rely on a common conceptual argument, the compatibility hypothesis, to show that the satisfaction- loyalty relationship is enhanced when attributes that drive satisfaction are also similarly used to affect loyalty. Our study extends the prediction-decision inconsistency outcome by uncovering the underlying process that contributes to such gaps between consumption/experience utility and decision utility. Hsee (1999, p. 560) stated that one of the limitations of his study resided in the assumption of knowing a priori the driver(s) of consumption utility. Our study addresses this by contending that when the drivers of consumption utility are similarly weighed in decision utility, the inconsistency between the two utilities will be attenuated.

The Nowlis and Simonson research is critically important because it demonstrates that compatibility effects are indeed possible within a purchase likelihood context. At the same time, it remains unclear just how pervasive they might be when introduced into a satisfaction and loyalty domain that are conceptually distinct.

\subsection{Consistency between compatibility effects and the evaluability hypothesis}

Hsee $(1996,1998)$ raises arguments similar to the compatibility hypothesis in his research on the evaluability hypothesis. He argues that, "when a person judges an option in isolation, the judgment is 
influenced more by attributes that are easy to evaluate than by attributes that are hard to evaluate, even if the hard-to-evaluate attributes are more important'” (Hsee, 1998, p. 109). In one experiment, Hsee (1996) had subjects evaluate two job candidates for a computer programming position that expected the programmer to be able to use a special computer language called KY. One candidate had written $70 \mathrm{KY}$ programs and had a GPA of 2.5 (grade point average based on a 5-point scale). The other candidate had written $10 \mathrm{KY}$ programs and had a GPA of 4.9. When evaluated separately, respondents were willing to pay more for the candidate with the higher GPA because they lacked benchmarks for evaluating programming experience. But when evaluated jointly, the relative weight given to programming experience increased.

Our predictions using the compatibility hypothesis are consistent with the evaluability hypothesis. Because satisfaction is a more isolated evaluation, easier to evaluate attributes (such as quality) in isolation should receive more weight while more difficult to evaluate attributes (such as price) in isolation should receive less weight.

The diagnosticity of price information is undermined unless some sort of distribution such as means and/or variances, is provided. Price becomes especially diagnostic when it can be compared with other price information. Unlike price, quality can be evaluated in isolation because it is more or less a subjective and personal judgment of the consumption experience. Because loyalty is a more comparative judgment, the relative weight of the more difficult to evaluate information in isolation (e.g., price) may increase under comparison or joint evaluation mode. On the other hand, the relative weight of the easier to evaluate information in isolation or separate evaluation mode (e.g., quality) may decrease.

The aforementioned arguments suggest that the relative weight of quality in loyalty evaluations will increase as it becomes easier to compare quality differences across alternatives. Internet websites such as consumerReports.org, comparison.com, and consumersearch.com have made possible enriched attributes such as quality into a comparable attribute, thereby increasing the weight attached to quality in making loyalty decisions.

According to the compatibility hypothesis, if quality (price) is difficult to compare due to its enriched characteristics, quality (price) is less compatible with loyalty evaluations because they require comparisons to like options. According to the evaluability hypothesis, if quality (price) is difficult to evaluate and compare across alternatives due to its subjective characteristics, quality (price) is less "evaluable" when judging loyalty again because they require comparisons to like options. Therefore, although we rely on the compatibility hypothesis to frame the problem and develop our predictions, we view these predictions as consistent with both the compatibility and evaluability hypotheses.

\section{Hypothesis development}

We focus on the relative importance of two general dimensions of product or service performance that drive customer satisfaction in the ACSI model: quality and price (Fornell et al., 1996). We acknowledge that this may be too simplistic a perspective to confine performance drivers of satisfaction to just two dimensions (i.e., quality and price). However, as Nowlis and Simonson (1997) postulate in their paper, "Our main focus is on preference tasks that are used most often to elicit consumer preferences - choice and ratings - and on the key attributes that consumers consider - price and quality" (p. 207). Therefore in an attempt to keep the model as parsimonious as possible, we too focus on the two key drivers of satisfaction, quality and price.

The relative importance of quality versus price (denoted relative quality importance or RQI) is revealed through the relative impact that perceived quality and perceived value have on customer satisfaction in the ACSI model. The impact scores involving perceived quality, perceived value, and customer satisfaction from the firm-level ACSI model estimations provide the information needed to operationalize a measure of quality-versus-price importance in evaluating satisfaction (Fornell et al., 1996). Thus, RQI is measured as (the effect of quality on satisfaction)/(the effect of value on satisfaction).

Certainly customers use a variety of benchmarks, including competitive products, to evaluate their satisfaction. Yet the focus is on the consumption experience. The purpose of a satisfaction evaluation is not to indicate a preference per se or one's predisposition toward choosing the product or 
service over competitors. Thus the weight that a customer places on information when evaluating loyalty vis-a-vis satisfaction should be more dependent on their ability to evaluate and compare differences across potential alternatives using that information.

This suggests that the compatibility of quality and price information in evaluations of customer loyalty should depend on the ease versus difficulty with which customers can judge and compare differences among potential substitutes on these dimensions. In this study, we focus on customers' ease versus difficulty in judging and comparing differences in quality within a product or service category (ease of judging/comparing quality differences or EQ). Compared to quality, price is a relatively concrete dimension on which consumers of varying knowledge and expertise can directly compare products and services (Nowlis \& Simonson, 1997). Following a strategy compatibility argument, the relative ease versus difficulty of judging and comparing quality differences in the category should systematically affect the use of quality information in loyalty evaluations. When it is relatively easy to judge and compare quality differences, quality information should have a greater impact on loyalty evaluations. As it becomes more difficult to judge and compare quality differences, the relative importance of price (quality) information should increase (decrease). These arguments are also consistent with the evaluability hypothesis (Hsee, 1996, 1998). Because satisfaction evaluations are more holistic and less comparative in nature, the ease or difficulty of judging and comparing quality differences should have less effect on the weight placed on quality information.

In short, the compatibility hypothesis suggests that when quality differences are easy to judge and compare, quality is more compatible with loyalty evaluations. Conversely, when quality differences are difficult to judge and compare, price is more compatible with loyalty evaluations. Therefore, the satisfaction-loyalty relationship should, as a result, depend on whether price or quality is similarly used to evaluate satisfaction and loyalty. Fig. 1 captures our conceptual model in that the relationship between satisfaction and loyalty is a function of two moderating variables, relative quality importance in judging satisfaction and the ease of judging and comparing quality differences among alternatives in a given category.

Consider a situation in which quality is relatively important to customers when evaluating satisfaction, such as our insurance example, but they do not feel confident in evaluating quality differences and making comparisons using such information when it comes to judging loyalty. The compatibility hypothesis suggests that, in this case, the weight placed on quality vis-a-vis price decreases from evaluations of satisfaction to evaluations of loyalty. This, in turn, should reduce the satisfactionloyalty relationship. As customers' ease of judging and comparing quality differences increases, quality information should be used equally in the two evaluations. This should increase the satisfaction-loyalty relationship. Overall, as price or quality information is weighed similarly in evaluations of both satisfaction and loyalty, we expect the relationship between satisfaction and loyalty to become stronger. We thus predict a three-way interaction in which the satisfaction-loyalty relationship becomes more positive when quality (price) is relatively more important in evaluations of satisfaction and customers find it easier (more difficult) to judge and compare quality differences in the category. 


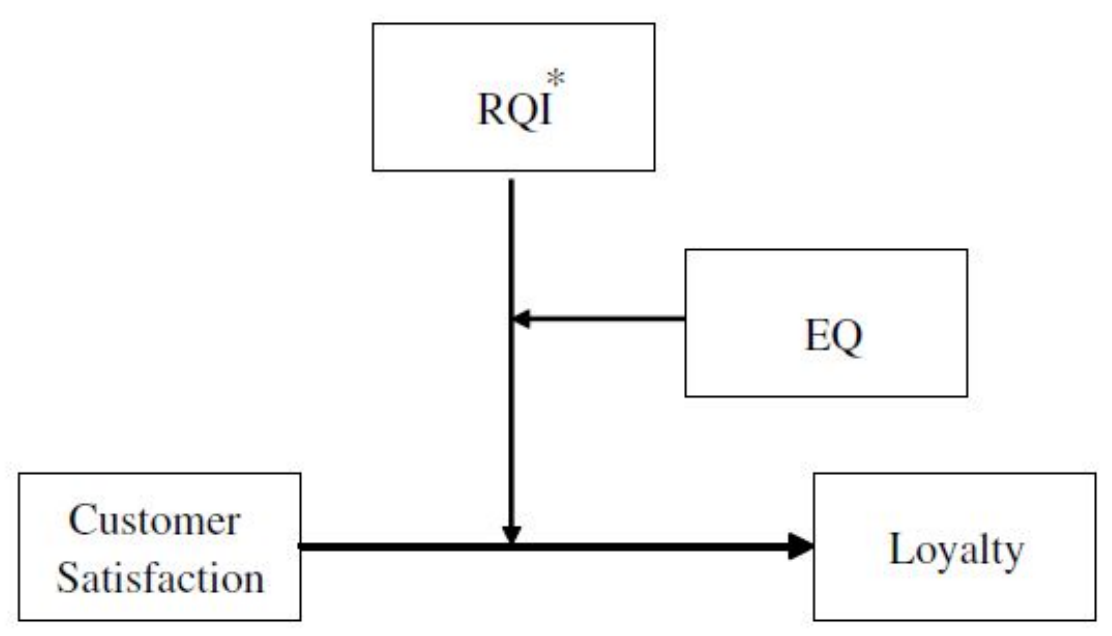

Fig. 1. Conceptual model.

Note: * RQI is a derived variable and refers to relative quality importance whereas EQ is a measured variable and refers to ease of judging and comparing quality. The conceptual model shows a three-way interaction whereby the effect of RQI on the satisfaction-loyalty relationship is dependent on EQ. In other words, the satisfaction-loyalty relationship is a function of both RQI and EQ.

An empirical study was conducted to test our main research hypothesis related to the satisfactionloyalty relationship. The proposed moderating effect serves as the basis for our main hypothesis. This hypothesis posits that the satisfaction-loyalty relationship is a function of both the relative importance of quality (versus price) in evaluating satisfaction (RQI) and the relative ease (versus difficulty) of evaluating and comparing quality differences (EQ). More specifically:

Hypothesis: The positive relationship between satisfaction and loyalty should become stronger as quality (price) becomes more important in evaluating satisfaction and it becomes easier (more difficult) to judge and compare quality differences.

Our prediction implies that satisfaction and loyalty will converge and become similar types of constructs when the information used to evaluate satisfaction is similarly utilized when making loyalty evaluations. For example, by making quality information easier to judge and compare across alternatives, this can be used instead of price. The merit of this is that it can deter firms from receiving a high rating on satisfaction (due to high quality) only to obtain a low score on loyalty (due to the difficulty of judging and comparing this quality information across alternatives when making loyalty decisions). Therefore, when relative importance of quality (RQI) is high in evaluating satisfaction and the relative ease (versus difficulty) of evaluating and comparing quality differences (EQ) is also high in evaluating loyalty, the association between satisfaction and loyalty will increase. It is worthy to note that what we are, in essence, suggesting is how the prediction-decision inconsistency can be reduced by using similar information to drive both satisfaction and loyalty.

In addition to our main hypothesis, a straightforward prediction of the compatibility hypothesis can be tested. This will ensure that the process that is driving our above three-way interaction effect is, in fact, due to the compatibility argument. Enriched attributes such as quality can be expected to have a greater impact than comparable attributes such as price on isolated evaluations such as satisfaction. Conversely, for comparable evaluations such as loyalty, we expect price to have the greater effect than 
quality. This suggests that firms with high quality and low value will score higher on satisfaction ratings while firms with low quality and high value will be rated higher on loyalty. Moreover, we would expect this compatibility effect to be more pronounced when the relative ease (versus difficulty) of evaluating and comparing quality differences (EQ) is low because this will make quality significantly more enriched increasing its diagnosticity in satisfaction while decreasing its diagnosticity in loyalty. We can therefore test for the interactive effect that EQ has with the type of firm (e.g., either high quality-low value or low quality-high value) in affecting satisfaction and loyalty. Consistent with the above predictions, the effect of quality will be greater in evaluating satisfaction than in determining loyalty while the impact of value will be greater in determining loyalty than in judging satisfaction.

A potential difficulty when estimating the relationship between satisfaction and loyalty is that the relationship may be non-linear. In competitive industries, customer loyalty may increase more at high than intermediate levels of satisfaction (Jones \& Sasser, 1995). It is important to test this prediction because a curvilinear relationship has the capacity to confound the proposed moderating effect. However, initial analyses using both a satisfaction main effect and satisfaction quadratic term to predict loyalty revealed no systematic non-linearity across the industry sectors studied. The following sections describe the empirical test of the hypothesis, the results, and their implications.

\section{Empirical study}

Firm-level observations from the 1994 and 1995 ACSI survey were used to test our research hypothesis (see Fornell et al., 1996, for details). We focus on four key constructs: perceived quality, perceived value, customer satisfaction, and customer loyalty.

Perceived quality is an index of customers' recent experience with the good or service using three measures: (1) overall perceived quality, (2) perceived customization, and (3) perceived reliability. These measures draw on the quality literature wherein customization, or "fitness for use,"' is distinguished from reliability, or "things gone wrong," as the primary components of quality (Deming, 1981; Juran \& Gryna, 1988). Two survey questions are used to operationalize perceived value: (1) quality received relative to price paid and (2) price paid relative to quality received. Three survey measures are used to operationalize customer satisfaction (ACSI): (1) an overall rating of satisfaction; (2) the degree to which performance falls short of or exceeds expectations; and (3) a rating of performance relative to the customer's ideal good or service in the category. These measures are consistent with the view that satisfaction is a cumulative or overall evaluation of the purchase and consumption experience to date in which customers use multiple performance benchmarks.

Finally the customer loyalty index uses two measures: (1) repurchase likelihood and (2) price tolerance. The price-tolerance measure is constructed from two survey questions: the degree to which a firm could raise its price(s) as a percentage before the customer would definitely not choose to buy from that firm again the next time (given the customer has indicated that he or she is likely to repurchase), and the degree to which a firm would have to lower its price(s) as a percentage before the customer would definitely choose again from that firm the next time (given the customer has indicated that he or she is unlikely to repurchase). As described earlier, this loyalty index measures whether customers are predisposed to purchase from a particular product or service provider again. The index provides a better overall measure of customer loyalty than a repurchase intention or likelihood measure alone. It also provides a common dependent variable for making broad-based comparisons of the satisfaction-loyalty relationship.

Survey questions are rated on 10-point scales and weighted to produce 0-100 point index scores for each construct. Firm-level data is used because a measure of RQI, the relative impact of quality versus price information on satisfaction, is required to test our proposed interaction. This measure is available from firm-level ACSI model results (described subsequently). Seven major economic sectors (1-digit SIC code level) are included in the ACSI design: manufacturing non-durables; manufacturing durables; transportation, communications and utilities; retail; finance and insurance; other services; and public administration and government. For each firm included in the survey in a given year, approximately 250 interviews are conducted with the firm's current customers to estimate the model. 
The 1994 baseline data includes survey information on 203firms across 40 industries and seven industry sectors while the 1995 update includes information on 201 firms across 35 industries and seven sectors. Specific food product categories (canned food, chocolate, milk and ice cream, baked goods, cold meats, and cold cereals) were reclassified more generally as processed foods between 1994 and 1995, which explains the change in industries studied. The six food processing categories from 1994 were subsequently collapsed into a single industry to have comparable observations for the two years. For the purposes of this study, public/government agencies were not included because of the relative lack of consumer choice, or "fforced loyalty,"' in this sector. We focus on the six remaining industry sectors. 3 For the purpose of the study, the two years worth of data were stacked to form an aggregated data set. Since some companies did not overlap across 1994 and 1995, only the companies that were included in both years were chosen for analysis. A total of 183firms were in both data sets yielding a total of 366 observations. A variable was included in the model estimations to capture the difference between the two years.

\subsection{Moderating variables and model specification}

Recall that relative quality importance or RQI is simply the ratio of the impact of quality on satisfaction over the impact of value on satisfaction in the ACSI model estimations. When quality is more important in driving satisfaction (high RQI), the impact of quality on satisfaction is high relative to the impact of value on satisfaction. Likewise, when price is more important in driving satisfaction (low RQI), the impact of quality is low relative to the impact of value. Note that the ACSI model does not provide an estimate of the impact of price per se on satisfaction (however, see Johnson et al., 2001, for exception). We discuss the implications of this in greater depth later in the paper. However, the value construct explicitly contains price information (quality received relative to price paid and price paid relative to quality received) while the quality construct does not. Thus changes in the RQI measure do reflect relative changes in the impact of price versus quality on satisfaction.

The correlation between quality and value in our data was $0.52(\mathrm{p}<0.001)$ suggesting that only $25 \%$ of the variance of value was explained by quality. Thus, this provides reassurance that these are distinct and discriminant constructs. We also draw upon the work of Zeithaml (1988) where exploratory study results revealed that a significant portion of respondents equated perceived value with perceived price. Some of the remarks expressed by respondents suggested that value is low price or value is the lowest price for a quality brand. Studies in the marketing industry also support this contention of equating value with price (Bishop, 1984; Schechter, 1984). Further support for a price interpretation of value comes from a recent study conducted by Sweeney and Soutar (2001). In their development of the PERVAL scale, a multi-item scale measuring perceived value, a distinct dimension of price emerged in explaining perceived value. Although from a conceptual perspective it may be better to tease out quality from price, value may be a more useful and diagnostic cue to use when making loyalty evaluations compared to price alone (Thaler, 1985). Anecdotal evidence and managerial experience calls for consumers using more than just price in determining loyalty, especially for high priced items (e.g., cars and appliance). They are more likely to weigh price and quality information together, which is precisely what value is, in making loyalty decisions. In short, whereas consumers would be unlikely to choose based on merely the lowest price (price minimization strategy) due to inference making about the corresponding quality, consumers would be more likely to choose based on value maximization. Making loyalty decisions based on value can also be easier to justify and explain, supporting a reason-based choice strategy (Shafir, Simonson, \& Tversky, 1993; Simonson, 1989).

The other moderating variable, ease of judging and comparing quality differences (EQ), is a measure collected as part of the ACSI survey but not included in the ACSI model estimation (National Quality Research Center, 1998). Each respondent is asked to judge their ability to evaluate quality differences using the following question: "Thinking about the quality of (insert product or service category), do you consider it difficult or easy to judge what is high versus low quality?'” The question is rated on a scale from 1 (very difficult) to 10 (very easy). Firm-level averages on this variable were used to measure EQ. 
A general linear model was estimated using five firm-level variables: customer satisfaction index scores (SAT), customer loyalty index scores (LOY), whether the data is from 1994 or 1995 (YEAR), relative quality importance (RQI), and the average ease of judging and comparing quality differences (EQ). All of the measures (including interaction terms) were mean centered within industries as our hypotheses center on competition among firms competing at this level. Mean centering of the variables also avoids multi-collinearity, especially for interaction terms (Bradley \& Srivastava, 1979; Jaccard, Turrisi, \& Wan, 1990). The model used to test our main hypothesis is expressed as follows:

$$
\begin{aligned}
\mathrm{LOY}= & b_{0}+b_{1} \mathrm{SAT}+b_{2} \mathrm{RQI}+b_{3} \mathrm{EQ}+b_{4} \mathrm{YEAR}+b_{5}(\mathrm{SAT} * \mathrm{RQI}) \\
& +b_{6}(\mathrm{SAT} * \mathrm{EQ})+b_{7}(\mathrm{RQI} * \mathrm{EQ})+b_{8}(\mathrm{SAT} * \mathrm{RQI} * \mathrm{EQ})+\varepsilon
\end{aligned}
$$

where b1 through b4 represent main effects and b5 through b8 represent interaction terms. Our main hypothesis and focal interest predicts that b8 will be positive and significant. That is, the satisfactionloyalty relationship increases when quality is more (versus less) important when evaluating satisfaction and it is relatively easy (versus difficult) to judge and compare quality differences. A general linear model estimation of model (1) was performed first across all 366 firm-level observations and then for each of the six industry sectors to provide further insight.

Also, to test our straightforward compatibility hypothesis on satisfaction and loyalty, we categorized firms into two groups (i.e., firm type) based on their level of quality and value. These two groups reflected a high quality-low value firm and a low quality-high value firm. To further test the interactive role that EQ may exert on this compatibility effect, we dichotomized EQ into low and high EQ based on a median split. We used t-tests to compare the mean satisfaction and loyalty scores on the firm type variable. Finally, to test the moderating role of EQ on this relationship, we ran two ANOVAs with satisfaction and loyalty as the dependent variables and firm type and EQ as the independent variables.

\subsection{Results}

Model (1) estimation results for the overall sample as well as those firms within particular industry sectors are presented in Table 1. Looking first at the overall results, there is a significant positive main effect of satisfaction on loyalty. Thissupports the vast body of research between satisfaction and loyalty in the context of potentially moderating effects. There is also a significant negative effect for year, which is consistent with the

Table 1

\begin{tabular}{|c|c|c|c|c|c|c|c|}
\hline $\begin{array}{l}\text { Variables, } \\
\text { sample size } \\
(N) \text {, and fit }\end{array}$ & Overall & $\begin{array}{l}\text { Manufac- } \\
\text { turing } \\
\text { non-dura- } \\
\text { bles }\end{array}$ & $\begin{array}{l}\text { Manufac- } \\
\text { turing } \\
\text { durables }\end{array}$ & $\begin{array}{l}\text { Transporta- } \\
\text { tion, com- } \\
\text { munica- } \\
\text { tions, and } \\
\text { utilities }\end{array}$ & Retail & $\begin{array}{l}\text { Finance } \\
\text { and } \\
\text { insurance }\end{array}$ & $\begin{array}{l}\text { Other } \\
\text { services }\end{array}$ \\
\hline Intercept & 0.453 & 0.618 & -0.248 & 0.549 & -0.250 & $2.281 * * *$ & -0.593 \\
\hline SAT & $0.569 * * *$ & $0.539^{* * *}$ & $0.796^{* * *}$ & $0.685^{* * *}$ & $0.540 * * *$ & $0.402 * * *$ & 0.211 \\
\hline RQI & -0.271 & $-1.079 * *$ & 0.390 & 0.089 & -0.029 & -1.124 & -0.252 \\
\hline EQ & 0.564 & -0.361 & $2.338^{*}$ & -0.292 & -2.684 & -0.990 & 5.153 \\
\hline YEAR & $-0.890^{* * *}$ & -0.636 & $-1.045^{* *}$ & $-1.066^{*}$ & -1.086 & -0.905 & -0.123 \\
\hline $\mathrm{SAT} * \mathrm{RQI}$ & 0.041 & 0.289 & -0.245 & -0.126 & 0.316 & -0.428 & -0.367 \\
\hline $\mathrm{SAT} * \mathrm{EQ}$ & -0.087 & -0.294 & 0.203 & 0.090 & $1.052^{*}$ & $-42.153 * *$ & $1.417^{*}$ \\
\hline $\mathrm{RQI} * \mathrm{EQ}$ & -0.054 & 0.603 & 1.946 & -1.462 & 1.797 & 0.925 & 5.503 \\
\hline $\begin{array}{l}\mathrm{SAT} * \\
\quad \mathrm{RQI}{ }^{*} \mathrm{EQ}\end{array}$ & $0.566^{* * *}$ & 0.579 & -1.197 & $0.917^{* *}$ & 1.335 & $2.540 * *$ & 1.648 \\
\hline$N$ & 366 & 102 & 70 & 78 & 56 & 30 & 30 \\
\hline$R^{2}$ & 0.374 & 0.195 & 0.756 & 0.566 & 0.404 & 0.465 & 0.403 \\
\hline Adjusted $R^{2}$ & 0.360 & 0.126 & 0.724 & 0.516 & 0.302 & 0.261 & 0.176 \\
\hline
\end{tabular}

Estimation results overall and within industry sectors (unstandardized regression coefficients)

Note: ${ }^{*} p<0.10,{ }^{* *} p<0.05,{ }^{* * *} p<0.01$ (two-tailed test). 
overall decline in the ACSI from 1994 to 1995. More important is the overall three-way interaction involving satisfaction, relative quality importance, and ease of judging and comparing quality that is positive and highly significant. In support of our hypothesis, and consistent with the compatibility hypothesis, the satisfaction-loyalty relationship is enhanced in those cases where quality is more important in evaluations of satisfaction and quality differences are relatively easy to judge and compare. None of the two-way interactions approached significance for the overall sample.

To further bolster our results, we ran another regression with RQI operationalized as the impact of value on satisfaction over the impact of quality on satisfaction (RVI) as opposed to the impact of quality on satisfaction over the impact of value on satisfaction (RQI). When this ratio was used in lieu of the original RQI ratio, the three-way interaction was negative and significant (b8 1/4 $\_0: 154, p<0: 005$ ). This suggests that as the relative quality (value) importance decreases (increases) in evaluating satisfaction and EQ increases, satisfaction and loyalty become more distinct constructs such that the satisfaction-loyalty relationship decreases.

The industry sector-level results provide insight as to which sectors contribute most to the overall results. The satisfaction-loyalty relationship is positive and significant in five of the six industry sectors, the exception being other services (hospitals, hotels, and motion picture providers). Although there is no main effect for satisfaction in this case, there is a marginally significant positive two-way interaction involving satisfaction and ease of judging and comparing quality. This suggests that the relationship between satisfaction and loyalty is positive, but only among those customers who find it relatively easy to judge and compare quality differences in this sector. Another central observation from Table 1 is the degree to which the predicted three-way interaction varies across sectors. This interaction is positive and significant for the transportation, communications, and utilities sector as well as the finance and insurance sector. The effect is positive and non-significant for manufacturing nondurables, retail and other services, and negative and non-significant for the manufacturing durables sector.

We now report the results of our basic compatibility hypothesis test and the moderating role of EQ. When satisfaction was the dependent variable, high quality-low value firms scored higher than low quality-high value firms (SAT $=0.53$ versus $\mathrm{SAT}=-0.27, \mathrm{~F}(1,90)=3.80, \mathrm{p}=0.05$ ). When loyalty was the dependent variable, low quality-high value firms were rated higher than high quality-low value firms although the difference was not statistically significant $(\mathrm{LOY}=0.37$ versus $\mathrm{LOY}=-0.33, \mathrm{~F}(1,90)=1.59$, $\mathrm{p}<0.22)$. Our findings generally support the compatibility hypothesis in that for satisfaction evaluations, firms that had high quality and low value outperformed those with low quality and high value. This was less so for loyalty, although it was in the expected direction.

To provide further insight into the basic compatibility hypothesis, we used regression as an alternative method. More specifically, we utilized the restricted least squares (RLS) method to test for linear equality restrictions (Gugarati, 1995, p. 256). The RLS method is used to test for linear equality constraints between regression coefficients in a given regression equation by comparing an unrestricted equation to a restricted equation (that which satisfies the linear constraint). For our analysis, the focal interest rested on the comparison of the regression coefficients between quality and value when satisfaction and loyalty were the dependent variables. Consistent with our earlier predictions, when satisfaction is the dependent variable, we would expect to see the coefficient of quality to be greater than that of value and vice versa when loyalty is the dependent variable. This test involved comparing the unrestricted regression equation to the restricted regression equation and using the general $\mathrm{F}$ testing method.

As shown in Table 2, when satisfaction was the dependent variable, the effect of quality was greater than the effect of value $(F(1,363)=24.60, p<0.001)$. Conversely, when loyalty was the dependent variable, the effect of value was greater than the effect of quality $(F(1,363)=4.08, p<0.05)$. Our regression results strongly confirmed a compatibility effect at work. When the two methods of analysis are taken collectively, they both converge and provide strong support for a compatibility hypothesis.

We conducted additional tests to obtain a deeper understanding of the compatibility hypothesis. To this end, we ran regressions to determine if the impacts of quality and value on satisfaction and loyalty 
were the same. Our prediction is that the effect of quality is greater on satisfaction than on loyalty while the impact of value is greater for loyalty than for satisfaction. We used the Chow test (Chow, 1960) to first examine if the regression coefficients for quality and value were identical when the dependent variables were satisfaction and loyalty. Results suggested that the coefficients associated with quality and value for satisfaction and loyalty were not the same $(\mathrm{F}(1,726)=12.94, \mathrm{p}<0.001)$. This test is an omnibus test and only tells us that the two regression equations (i.e., satisfaction and loyalty) are different but does not inform us about the source of the difference. A theoretically and empirically more stimulating question would be, is the difference in the two regression equations due to the difference in the coefficients associated with quality, the coefficients related

Table 2

Compatibility hypothesis test (unstandardized regression coefficients)

\begin{tabular}{|c|c|c|c|c|}
\hline $\begin{array}{l}\text { Variables, sample size }(N) \text {, and } \\
\text { residual sum of square (RSS) }\end{array}$ & SAT $\left(\mathrm{UR}^{\mathrm{a}}\right)$ & $\operatorname{SAT}\left(\mathrm{RR}^{\mathrm{b}}\right)$ & LOY (UR) & LOY (RR) \\
\hline Intercept & $-0.321 * * *$ & $-0.303^{* * *}$ & $-0.257^{*}$ & $-0.268 *$ \\
\hline QUALITY & $0.636^{* * *}$ & & $0.241^{* * *}$ & \\
\hline VALUE & $0.333 * * *$ & & $0.416^{* * *}$ & \\
\hline QUALITY + VALUE & & $0.466^{* * *}$ & & $0.339 * * *$ \\
\hline$N$ & 366 & 366 & 366 & 366 \\
\hline$R^{2}$ & 0.69 & 0.66 & 0.36 & 0.35 \\
\hline RSS & 1392.74 & 1487.11 & 2848.92 & 2880.68 \\
\hline
\end{tabular}

to value or is due to both? In order to identify the source that is contributing to the difference in the two equations, a pooled regression as shown below was estimated using dummy variables (Gugarati, 1995).

$$
\begin{aligned}
Y= & b_{0}+b_{1} \text { QUALITY }+b_{2} \text { VALUE }+b_{3} D+b_{4}(D * \text { QUALITY }) \\
& +b_{5}(D * \text { VALUE })+\varepsilon,
\end{aligned}
$$

where $\mathrm{D}=0,1$ for satisfaction and loyalty, respectively. Results were promising in that the interaction between D and QUALITY was significant (b4 $=-0.395, \mathrm{p}<0.001$, one-tailed test). The coefficient for $\mathrm{D} *$ VALUE was also marginally significant ( $\mathrm{b} 5=0.836, \mathrm{p}<0.07$, one-tailed test). Once the estimated coefficients were inserted into the above equation, the coefficients for quality were 0.636 and 0.241 when satisfaction and loyalty were the dependent variables, respectively. Also, the coefficients for value were 0.333 and 0.416 when satisfaction and loyalty were the dependent variables, respectively. Therefore, the effect of quality is greater in satisfaction than in loyalty while the effect of value is greater in loyalty than in satisfaction. In conclusion, by employing multiple methods and reaching consistent findings, we are able to add considerable confidence to a compatibility hypothesis at work in our data.

The results of ANOVA that tested the moderating role of EQ on the above compatibility are somewhat more complex. When satisfaction was the dependent variable, the interaction between firm type and EQ was not significant $(F(1,92)=0.850$, $p>0.30)$. However, upon closer observation, the difference in satisfaction ratings between the high quality-low value firms and the low quality-high value firms was more pronounced when EQ was low than high (low EQ: SAT $=0.68$ versus SAT $=-0.49, \mathrm{~F}$ $(1,41)=3.56, \mathrm{p}<0.07$ and high EQ: SAT $=0.47$ versus $\mathrm{SAT}=0.10, \mathrm{~F}(1,47)=0.37, \mathrm{p}>0.50)$. When 
loyalty was the dependent variable, this was qualified by a significant interaction between firm type and EQ $(F(1,92)=5.56, p<0.05)$. However, closer examination revealed that the results were counter to what we had expected. In other words, opposite to what we had expected, the difference in loyalty was greater between the low quality-high value firms and the high quality-low value firms under high EQ than low EQ (high EQ: LOY = 1.51 versus LOY $=-0.62$, F $(1,47)=8.79, \mathrm{p}<0.01$ and low EQ: LOY = 0.31 versus $\mathrm{LOY}=0.28, \mathrm{~F}(1,41)=0.41, \mathrm{p}>0.50)$. We performed a final analysis to better inform us of the three-
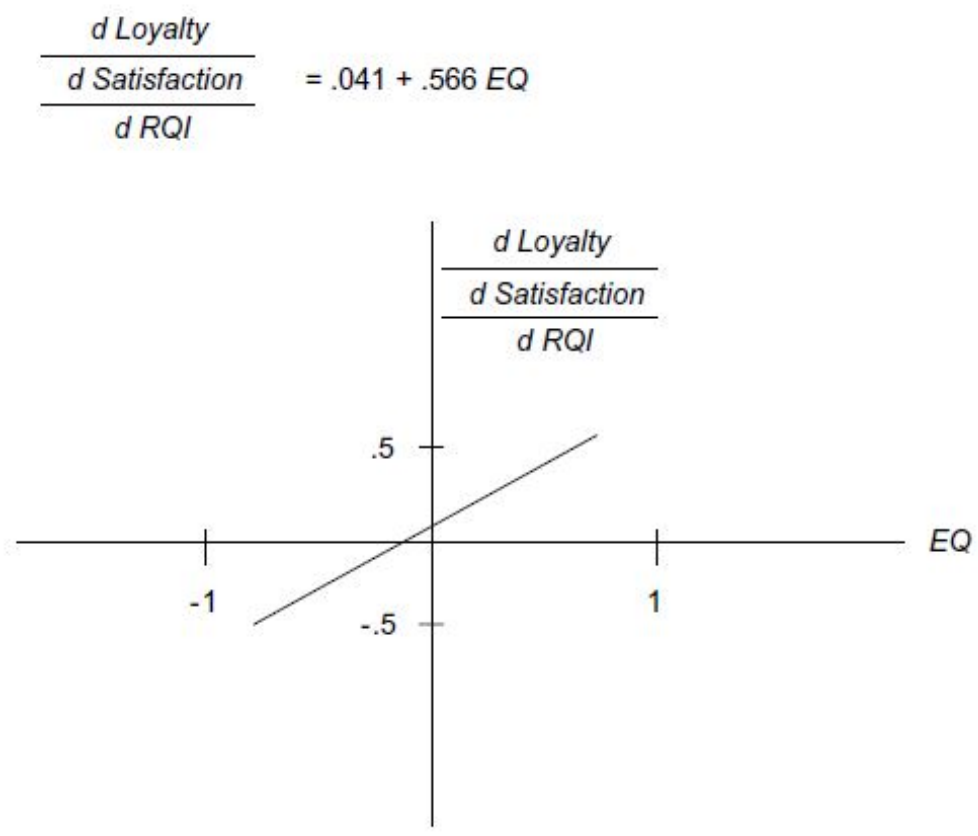

Fig. 2. The effect of RQI on the satisfaction-loyalty relationship over the range of EQ.

way interaction. According to this procedure, it is possible to examine the extent to which RQI moderates the satisfaction-loyalty relationship over the range of EQ. Our positive three-way interaction would suggest that when dissimilar information is used to evaluate satisfaction and loyalty, the relationship between satisfaction and loyalty is negative. However, when similar information is used to evaluate both satisfaction and loyalty, the relationship between satisfaction and loyalty is positive. This implies that the effect of RQI on the satisfaction-loyalty relationship is non-monotonic with its effect shifting over the range of EQ. We tested for the non-monotonic effect using the procedure outlined by Garg, Walters, and Priem (2003) and Schoonhoven (1981). Fig. 2 shows the results of our analysis. According to Fig. 2, the satisfaction-loyalty relationship is negative when dissimilar information (e.g., high RQI-low EQ) is used to evaluate satisfaction and loyalty while the relationship turns positive when similar information (e.g., high RQI-high EQ) is used to evaluate the two constructs. These results are consistent with the negative three-way interaction obtained when relative value importance (RVI) was used instead of RQI. In conclusion, the effect of RQI on the relationship between satisfaction and loyalty seems to be nonmonotonic over the range of EQ.

\section{Summary and discussion}

To recapitulate, the results from our study make contributions to the literature on satisfaction and loyalty by using a compatibility argument. Our research extends this literature by showing that when price and quality information is used similarly in both satisfaction and loyalty evaluations, the relationship 
between the two constructs is strengthened. Furthermore, our study sheds light into the process by which the prediction-decision inconsistency can be reduced (Hsee, 1999). The results of our study articulate the underlying process by which the satisfaction-loyalty relationship can be strengthened and also provides managerial implications of how companies can better manage customer relationships using such findings.

Our results, although not a direct test of the preference reversal phenomenon per se, do imply that the satisfaction-loyalty link can be strengthened when the underlying process that contributes to preference reversal (e.g., differential weighting of information used to evaluate satisfaction and loyalty) is deterred. This was supported when we operationalized RVI instead of RQI and included this variable in the three-way interaction and also from our finding that suggested the effect of RQI on the satisfactionloyalty relationship to be non-monotonic over the range of EQ. In such a case, the satisfaction-loyalty relationship was negative when information was weighed differentially between satisfaction and loyalty but became positive as similar information was used between the two constructs. In light of our results, this study extends our knowledge in the domain of why does not consumption utility lead to decision/choice utility? Moreover, it provides prescriptive guidance on how to overcome the discrepancy between satisfaction as a type of experience and consumption utility and loyalty as a type of decision or choice utility.

Using what behavioral scientists have used in controlled laboratory settings, this research adopts the compatibility argument in an applied managerial context using a large survey based dataset. These findings are important as they demonstrate the relevance of compatibility effects in an applied, customer satisfaction context. Rather than rely on evaluations of hypothetical alternatives in a controlled, laboratory setting, we used a large national survey in which customers reported on their actual experience with products and services offered by 183 different companies across 30 categories. An important benefit of using such data is that it is difficult to explain our findings on the basis of task or demand characteristics.

We relied on multiple variations of analyses to test our basic compatibility argument. Taken collectively, the results of our study generally support the presence of a compatibility effect. Our findings supported the expectation that quality would have a greater impact than price in explaining satisfaction and vice versa in determining loyalty. We also found partial support for this when firms were dichotomized into high quality-low value firms and low quality-high value firms. Satisfaction ratings were higher for the high quality-low value firms than for the low quality-high value firms. In accordance with the compatibility hypothesis, loyalty evaluations were higher for the low quality-high value firms than for the high quality-low value firms, albeit not statistically significant. For expositional reasons, we chose two firms, one of high quality-low value and the other of low quality-high value. Results revealed that the high quality-low value firm was rated higher in satisfaction compared to the low quality-high value firm while the reverse was true for loyalty in that the low quality-high value firm was rated higher than the high quality-low value firm. We also showed that the effect of quality was greater in evaluating satisfaction than loyalty while the impact of value was higher in evaluating loyalty than satisfaction.

Taken collectively, our study has shown a robust compatibility effect explaining the difference between satisfaction and loyalty and depending on how the weight of information used to evaluate the two constructs shifts, the strength of the relationship between satisfaction and loyalty changes accordingly.

However, we obtained mixed results when we tested to see if EQ would moderate this basic compatibility effect. In explaining satisfaction, we did find that the difference in satisfaction ratings was greater between the high quality-low value firms and the low quality-high value firms under low EQ than high EQ. When determining loyalty, though, our results revealed an opposite finding in that the difference in loyalty evaluations was greater between the low quality-high value firms and the high quality-low value firms under high EQ than low EQ. The interpretation of this finding is much more challenging. It may be the case that in order for consumers to use value in evaluating loyalty, consumers may need to 
rationalize themselves that value is indeed more diagnostic than quality. When EQ is low, this is not feasible as it may be difficult to compare low and high quality. The diagnosticity of value increases and hence is weighed more heavily in loyalty evaluations only after it has been determined that quality is a comparable attribute. Since quality is used as input in determining value, unless EQ is high, a reliable value cannot be mentally construed. Therefore, EQ should be high to facilitate the use of value as a diagnostic cue in making informative loyalty decisions. This implies that the weight of value is heightened in loyalty decisions only when it is easy to judge and compare quality differences across alternatives.

Finally, we showed that the effect of RQI on the satisfaction-loyalty relationship was nonmonotonic over the range of EQ. This is a very informative finding in that it suggests that the satisfaction-loyalty relationship may not always be positive as thought. Rather, our results indicate that it can change from negative to positive as price or quality information that is used in satisfaction evaluations is similarly used in loyalty decisions. When information alignment exists in evaluations of satisfaction and loyalty, we can expect the relationship between the two constructs to be enhanced. Another reasonable explanation for the negative relationship between satisfaction and loyalty when attributes used in satisfaction are different from those used in loyalty can be that firms, in our particular dataset or more generally in the market, are distributed along the Pareto optimal frontier. This suggests that firms with higher (lower) quality are likely to offer worse (better) price or value. Under such distribution of firms, higher satisfaction (due to higher quality) would be correlated with lower loyalty (due to worse price or value).

Recall our example at the outset of the paper about the insurance company. Imagine that a customer is satisfied with an insurance company mainly due to its high service quality and the time has come to make a decision as to whether he/she should continue this relationship or switch to another company. However, the customer cannot differentiate the quality difference among alternatives and hence is unable to make informative comparisons either due to lack of personal knowledge or lack of public information. According to our study, this should attenuate the relationship between satisfaction and loyalty.

In our database, the average EQ was the lowest for the finance and insurance sector (7.075) among the six sectors. Given that this is true, according to the compatibility argument, the satisfactionloyalty relationship will increase when satisfaction is mainly driven by price. The implication that follows from this is that such financial companies can be successful at maintaining customer relationships by providing reasonable quality at an attractive price (i.e., aggressive pricing strategy). Companies such as Charles Schwab have been extremely successful by delivering satisfaction at a competitive price. On the other hand, what would this mean for companies such as Fidelity or Prudential that provide a more customized service that tailors to customers' needs? Our research suggests that for companies such as these, they need to develop marketing tools and communication strategies to educate customers on how their company is superior on these quality dimensions compared to their competitors in order to facilitate quality differentiation. Only then will clients be less likely to weigh price more heavily in making loyalty decisions over alternatives. Our argument and results are also consistent with the finding that preference reversals can be reduced when enriched attributes such as brand name and country of origin are made more comparable (Nowlis \& Simonson, 1997).

The primary contribution of this research is its support for a compatibility-based explanation for observed variation in the relationship between customer satisfaction and loyalty. At the heart of this effect is a subtle but important difference between two closely related constructs, satisfaction and loyalty. Whereas satisfaction focuses on a customer's experience with a particular product or service, loyalty focuses more on the customer's expectation or predisposition to choose that product or service over alternatives. As a result, the relative importance of quality and price information may vary between the 
two evaluations. When quality is important to a customer's satisfaction but they find it difficult to judge and compare quality differences, quality is more likely to be used in evaluations of satisfaction than in evaluations of loyalty. When quality is important and it is easy to judge and compare quality differences, quality is used more equally whether evaluating satisfaction or loyalty. As a result, the relationship between satisfaction and loyalty increases.

Our findings suggest important relationship maintenance strategies for novice customers especially in industries such as the financial sector where significant discrepancy exists between customers who have a working knowledge of the industry compared to those that do not. If, for example, a relatively novice customer is very satisfied with the service and quality received from a highly reputable financial company and has to make a decision whether to continue this relationship or not, the presence and availability of information on quality differences among alternatives that facilitates and bolsters the superiority of the current service and quality should lead to a greater likelihood of relationship maintenance.

Our results also have important implications for satisfaction modeling, customer retention strategies, and the priority setting process. Satisfaction models have focused primarily on main effects. This is due, in part, to the cause and effect nature of satisfaction research where customer satisfaction sits within a larger system of relationships. The result has been an emphasis on mediating rather than moderating effects. Our results reinforce the need to focus more on moderating effects within a customer satisfaction framework. It is also valuable for a firm to understand whether the factors that influence customer satisfaction similarly influence customer loyalty. Consider two firms for whom quality and price have equivalent impacts on customer satisfaction. Looking only at these impacts, both firms could increase satisfaction and subsequent loyalty either through increasing quality or decreasing price by comparable levels. If, however, price has the greater impact on loyalty for one firm and quality has the greater impact on loyalty for the other, very different strategies emerge.

Finally, the study has implications for the priority setting process and consequently for resource allocation in product developments. Typically, the most important drivers to improve are those where the impact on satisfaction is high and performance is poor. In order for marketing managers to reap the rewards of high customer satisfaction and increased loyalty, they need to make sure that the factor(s) which contribute to high satisfaction are equally weighted when customers make loyalty decisions. Yet this process could be misleading if there are significant moderating effects on customer loyalty. Looking only at the impact of the drivers on satisfaction may overestimate or underestimate their effect on loyalty and subsequent behavior.

\section{Limitations and future research directions}

As with most research, this study also has its limitations. We operationalized RQI as the ratio between the impact of quality on satisfaction over the impact of value on satisfaction. As was mentioned earlier, we did not have the effect of price on satisfaction per se. Johnson et al. (2001) argues that the ACSI model has the tendency to be tautological in this respect. In other words, since quality is also a component of perceived value, the relationship can be confounded. Thus, a stricter test of our model would have been to operationalize RQI with a pure effect from price to satisfaction. The recent development of the Norwegian Customer Satisfaction Barometer (NCSB) takes the initial step in this direction by incorporating a more pure price construct in its model (Johnson et al., 2001).

Also, the correlational design of the study does not allow for a strict test of causality between satisfaction and loyalty. Despite the widespread acceptance of the relationship between satisfaction and loyalty, it is interesting to note the scarcity of research that has adopted a more controlled setting using an experimental design to examine the causality between satisfaction and loyalty. For some consumers, 
variables such as trust and commitment maybe more important than satisfaction in determining loyalty (Garbarino \& Johnson, 1999).

Satisfaction research has been criticized for not being able to predict customer retention. Voices have been raised about satisfied customers not being loyal and the disappointment that satisfaction research has produced (Jones \& Sasser, 1995). We believe our study has taken a step in this direction by delineating the conditions under which the satisfaction-loyalty relationship can be enhanced.

\section{Acknowledgements}

The authors thank the associate editor, reviewers, J. Frank Yates and other members of the University of Michigan's Decision Consortium for their constructive comments on the paper. We also gratefully acknowledge the University of Michigan Business School's National Quality Research Center and ASQ, the American Society for Quality, for providing the data used in the study. 


\section{References}

Anderson, E., Fornell, C., \& Lehmann, D. (1994). Customer satisfaction, market share and profitability: Findings from Sweden. Journal of Marketing, 58, 53-66.

Anderson, E., \& Mittal, V. (2000). Strengthening the satisfaction-profit chain. Journal of Service Research, 3, 107-120.

Bettman, J. R., Luce, M. F., \& Payne, J. W. (1998). Constructive consumer choice processes. Journal of Consumer Research, 25, 187-217.

Billings, R. S., \& Scherer, L. L. (1988). The effects of response mode and importance on decision-making strategies: Judgment versus choice. Organizational Behavior and Human Decision Processes, 41, 1-19.

Bishop, W. R., Jr. (1984). Competitive intelligence. Progressive Grocer (March), 19-20.

Bloemer, J. M. M., \& Kasper, H. D. P. (1995). The complex relationship between consumer satisfaction and brand loyalty. Journal of Economic Psychology, 16, 311-329.

Bradley, R. A., \& Srivastava, S. S. (1979). Correlation and polynomial regression. American Statistician, 33, 11-14.

Chow, G. C. (1960). Tests of equality between sets of coefficients in two linear regressions. Econometrica, 28, 591-605.

Deming, W. E. (1981). Management of Statistical Techniques for Quality and Productivity. New York University, New York, Graduate School of Business.

Fishbein, M., \& Ajzen, I. (1975). Belief, attitude, intention, and behavior: An introduction to theory and research. Reading, MA: Addison Wesley.

Fornell, C. (1992). A national customer satisfaction barometer: The Swedish experience. Journal of Marketing, 56, 6-21.

Fornell, C., Johnson, M. D., Anderson, E. W., Cha, J., \& Bryant, B. E. (1996). The American customer satisfaction index: Nature, purpose and findings. Journal of Marketing, 60, 7-18.

Garbarino, E., \& Johnson, M. S. (1999). The different roles of satisfaction, trust, and commitment in customer relationships. Journal of Marketing, 63, 70-87.

Garg, V. K., Walters, B. A., \& Priem, R. L. (2003). Chief executive scanning emphases, environmental dynamism, and manufacturing firm performance. Strategic Management Journal, 24, 725-744.

Gugarati, D. N. (1995). Basic Econometrics. McGraw-Hill.

Hsee, C. K. (1996). The evaluability hypothesis: An explanation for preference reversals between joint and separate evaluations of alternatives. Organizational Behavior and Human Decision Processes, 67, 247- 257.

Hsee, C. K. (1998). Less is better: When low-value options are valued more highly than high-value options. Journal of Behavior Decision Making, 11, 107-121.

Hsee, C. K. (1999). Value seeking and prediction-decision inconsistency: Why don't people take what they predict they'll like the most? Psychonomic Bulletin and Review, 6(4), 555-561.

Hunter, J. E. (2001). The desperate need for replications. Journal of Consumer Research, 28, 149-158.

Jaccard, J., Turrisi, R., \& Wan, C. K. (1990). Interaction effects in multiple regression. Newbury Park,

CA: Sage.

Johnson, M. D., Anderson, E. W., \& Fornell, C. (1995). Rational and adaptive performance expectations in a customer satisfaction framework. Journal of Consumer Research, 21, 128-140.

Johnson, M. D., Gustafsson, A., Andreassen, T. W., Lervik, L., \& Cha, J. (2001). The evolution and

future of national customer satisfaction index models. Journal of Economic Psychology, 22, 217-245.

Jones, T. O., \& Sasser, W. E., Jr. (1995). Why satisfied customers defect. Harvard Business Review, 73, 88-99.

Juran, J. M., \& Gryna, F. M. (1988). Juran's quality control handbook (4th ed.). New York: McGraw-

Hill. Kahneman, D., \& Varey, C. (1991). Notes on the psychology of utility. In: J. Elster \& J. E. Roemer (Eds.),

Interpersonal comparisons of well-being: Studies in rationality and social change, pp. 127-163. 
Lervik, L., \& Johnson, M. D. (2003). Service equity, satisfaction and loyalty: From transaction-specific to cumulative evaluations. Journal of Service Research, 5, 184-195.

Mittal, V., \& Kamakura, W. (2001). Satisfaction, repurchase intent, and repurchase behavior:

Investigating the moderating effect of customer characteristics. Journal of Marketing Research, 38, 131-143.

National Quality Research Center (1998). American customer satisfaction index (ACSI) methodology report: March 1998. Ann Arbor, MI: University of Michigan Business School.

Nowlis, S. M., \& Simonson, I. (1997). Attribute-task compatibility as a determinant of consumer preference reversals. Journal of Marketing Research, 34, 205-218.

Payne, J. W., Bettman, J. R., \& Johnson, E. J. (1992). Behavior decision research: A constructive processing perspective. Annual Review of Psychology, 43, 87-131.

Payne, J. W., Bettman, J. R., \& Johnson, E. J. (1990). The adaptive decision maker: Effort and accuracy in choice. In R. M. Hogarth (Ed.), Insights in decision making: A tribute to Hillel J.Einhorn (pp. 129-153). Chicago: University of Chicago Press.

Rust, R., \& Zahorik, A. (1993). Customer satisfaction, customer retention, and market share. Journal of Retailing, 69, 193-215.

Rust, R., Zahorik, A., \& Keningham, T. L. (1995). Return on quality (ROQ): Making service quality financially accountable. Journal of Marketing, 59, 58-70.

Schechter, L. (1984). A normative conception of value. Progressive Grocer, Executive report, 12-14.

Schoonhoven, C. B. (1981). Problems with contingency theory: Testing assumptions hidden within the language of contingency theory. Administrative Science Quarterly, 26, 349-377.

Shafir, E., Simonson, I., \& Tversky, A. (1993). Reason-based choice. Cognition, 49, 11-36.

Simonson, I. (1989). Choice based on reasons: The case of attraction and compromise effects. Journal of Consumer Research, 16, 158-174.

Slovic, P., Griffin, D., \& Tversky, A. (1990). Compatibility effects in judgment and choice. In R. M.

Hogarth (Ed.), Insights in decision makin : A tribute to Hillel J. Einhorn (pp. 5-27). Chicago:

University of Chicago Press.

Sweeney, J. C., \& Soutar, G. N. (2001). Consumer perceived value: The development of a multiple item scale. Journal of Retailing, 77, 203-220.

Szymanski, D. (2001). Customer satisfaction: A meta-analysis of the empirical evidence. Journal of the Academy of Marketing Science, 29, 16-36.

Thaler, R. H. (1985). Mental accounting matters. In D. Kahneman \& A. Tversky (Eds.), Choices, values and frames. Cambridge: Cambridge University Press.

Tversky, A., Sattath, S., \& Slovic, P. (1988). Contingent weighting in judgment and choice.

Psychological Review, 95, 371-384.

Zeithaml, V. A. (1988). Consumer perceptions of price, quality, and value: A means-end model and synthesis of evidence. Journal of Marketing, 52, 2-22. 